\title{
Emerging Therapies: Pleiotropic Multi-target Drugs to Treat Stroke Victims
}

\author{
Paul A. Lapchak
}

Received: 20 March 2011 / Accepted: 20 March 2011 / Published online: 12 April 2011

(C) Springer Science+Business Media, LLC 2011

\author{
"If you want to succeed you should strike out on new paths, rather \\ than travel the worn paths of accepted success." \\ John D. Rockefeller (1839-1937)
}

\section{Introduction}

Acute ischemic stroke (AIS) is a disease of heterogeneity [1]. In patients with strokes of known causes, cardioembolic stroke is the predominant subtype making up $29 \%$ of the population, whereas both atheroembolic and lacunar strokes are represented by $16 \%$ of the population $[2,3]$. Most stroke victims having multiple prevailing conditions prior to the onset of the devastating vascular event, such as hypertension or diabetes [1,4]. Based upon the patient population enrolled in a few prominent clinical trials, it is estimated that $80-90 \%$ of all stroke patients were medicated with a variety of pharmaceuticals including antihypertensives (i.e., $\beta$-blockers), angiotensinconverting enzyme (ACE) inhibitors, diuretics, calcium channel antagonists, 3-hydroxy-3-methylglutaryl-coenzymeA (HMG-CoA) reductase inhibitors (i.e., statins), platelet inhibitors (i.e., aspirin, clopidogrel), anticoagulants (i.e., warfarin), and antidepressants at the time of their stroke [1, 4-8]. Despite many preventative measures to reduce stroke incidence, stroke remains the third leading cause of death and leading cause of adult

P. A. Lapchak $(\bowtie)$

Translational Research, Cedars-Sinai Medical Center,

Department of Neurology, Burns and Allen Research Institute,

Davis Research Building, Room D-2091,

110 N. George Burns Road,

Los Angeles, CA 90048, USA

e-mail: Paul.Lapchak@cshs.org disability in the USA [9]. It is estimated that approximately 0.8 million victims suffer a stroke annually with $18 \%$ of victims dying. Even though there is a large population of stroke victims in the USA [9-12] and worldwide [13], and there is an enormous financial impact and burden to society [14], the arsenal of armaments to effectively treat stroke is limited to one thrombolytic agent that was originally developed to treat acute myocardial infarction [15-20] and subsequently approved for stroke on the basis of the National Institute of Neurological Disorders and Stroke (NINDS) trial [1]. However, it should be noted that in addition to the use of tissue plasminogen activator (tPA) in Japan, a single non-thrombolytic drug, which will be discussed, is also formally approved as a treatment [21].

\section{State-of-the-Art Treatments}

There are two structurally and mechanistically different drugs approved for the treatment of stroke: the thrombolytic tPA (Alteplase ${ }^{\circledR}$ ) and the pleiotropic antioxidant, edaravone (Radicut $\left.^{\circledR}\right)$.

Currently, in the USA, the only Food and Drug Administration (FDA)-approved treatment for acute stroke care is tPA $(0.9 \mathrm{mg} / \mathrm{kg}$ i.v. $)$, a plasminogen activator that promotes thrombolysis by activating the endogenous fibrinolytic system [22-25], and in $22-40 \%$ of patients promotes partial or full recanalization [26-31], but recanalization rates are highly variable. The article by Soltani and colleagues [32] in this issue of TSR elaborates on the use of sonothrombolysis to promote recanalization, either alone or in combination with tPA, but recanalization may be insufficient therapeutically. There is some evidence that the strategy can be beneficial, as detailed in the article, but 
technical aspects of ultrasound need to be further evaluated for safety and efficacy.

Although thrombolysis, which was first approved by the FDA in 1996, is now widely accepted as a standard of care, it is still underutilized. It is estimated that $2-4 \%$ of AIS patients are being treated with IPA in the USA [33, 34]. While there is no doubt that IPA is quite useful in up to $50 \%$ of patients given $\mathrm{tPA}$, that is $1-2 \%$ of the stroke patient population, depending on the type of ischemic stroke [1], tPA is not a breakthrough treatment for stroke, mainly because too few patients are being treated. There are important shortcomings of the drug including the fact that tPA does not confer neuroprotection. Alteplase has been shown to be effective up to $4.5 \mathrm{~h}$ after a stroke $[5,35]$, it is currently FDA-approved for use within a $3 \mathrm{~h}$ therapeutic window. Lastly, with tPA treatment, there is a significant risk of hemorrhagic transformation (HT) or intracerebral hemorrhage (ICH) in approximately $3 \%$ to $6 \%$ of patients treated within 3-4.5 h of a stroke [36] and the odds ratio for mortality

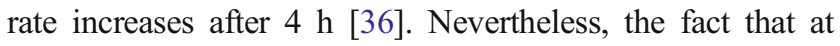
least one FDA-approved drug could be developed is an important proof of concept and an impetus for further drug development.

In Japan, in addition to the use of tPA at both low $(0.6 \mathrm{mg} / \mathrm{kg}$ i.v.) and standard $(0.9 \mathrm{mg} / \mathrm{kg}$ i.v. $)$ doses $[37,38]$, Edaravone (Radicut ${ }^{\circledR}$ ), a lipophilic free radical scavenger is approved by the Japanese Ministry of Health and Welfare (JMHW) to treat stroke patients presenting within $24 \mathrm{~h}$ of the attack. Edaravone is currently available in two formulations: injectable edaravone ampoules (30 $\mathrm{mg}$ b.i.d, i.v., 14 days), which were first approved in 2001, and the Radicut BAG that was approved in 2010, which delivers the same dose of drug. While edaravone is extensively used in Japan, and reports are surfacing from India and China [21, 39, 40], actual benefit spans from large significant clinical improvements to smaller improvements in clinical function measured using standard stroke scales. Unlike the possibly devastating side effects of tPA, after 18 years of clinical experience with edaravone, the main adverse effect is acute renal failure, which usually resolves after cessation of treatment.

\section{Time to Treat Victims}

There are two main therapeutic windows for successful intervention: The first opportunity is acute intervention within $24 \mathrm{~h}$ of a stroke, to intervene at the level of mediators of the ischemic cascade [41, 42], thereby blocking single or multiple components of the cascade during the early stages of ischemic stroke progression. This strategy may attenuate the neuronal degeneration and behavioral deficits. Experimental stroke research has identified many factors responsible for the death of neurons and glial cells following ischemic stroke. One of the primary causes of cell death is "energy failure" or depletion of high-energy phosphates, which occurs quickly after ischemia [43, 44]. In embolic strokes, impairment of the microcirculation may also be a contributing factor to the evolution of ischemia distal to the infarct. Immediately following an embolic stroke, excitatory amino acid neurotransmitters (glutamate) are released in excess quantity from presynaptic terminals and can propagate the ischemic response and also cause "delayed neuronal death" or the protracted necrosis of neurons [41, 42]. Also of great importance are the roles of free radical species, oxygen free radicals and superoxides, which are produced in abundance following ischemic injury and have been identified as possible mediators of ischemic necrosis and vascular damage [21, 42, 45]. Moreover, cascade mediators cause substantial injury to the "ischemic penumbra," a tissue that is potentially salvageable [46-48] if appropriate treatment can be administered in a timely fashion. The cells, primarily glial and neuronal, located in the penumbra are a valid target for neuroprotective agents since they may survive if the deleterious actions of specific mediators of the ischemic cascade are suppressed or blocked [46-48]. However, due to therapeutic window limitations for neuroprotective drugs, the majority of stroke victims will not receive adequate treatment [49]. The second opportunity is when neuroprotection may no longer be an option for acute intervention (i.e., $>24 \mathrm{~h}$ after a stroke). Thus, there may be a need for an intervention that can promote neuronal repair and enhance both neuronal and clinical function [42].

"Learning is not attained by chance, it must be sought for with ardor and attended to with diligence."

Abigail Adams (1744-1818)

\section{The Learning Curve}

Developing novel neuroprotective treatments for stroke has become a daunting task and some even question the validity or usefulness of neuroprotective strategies to treat stroke. Could it be that the right compounds are not being developed?

Almost all neuroprotective strategies to date have attempted a monotherapy against a single target. For example, several stroke clinical trials have evaluated neuroprotective agents which target free radicals $[21,39,50,51]$; however, the results are mixed. The continuing failure of acute neuroprotective drugs was emphasized in the NXY-059 SAINT II trial report [8]. The concept that a free radical scavenger may eventually be useful is not being challenged in this editorial. Free radicals are an important and very damaging component of the ischemic cascade and need to be suppressed (See edaravone and STAZN discussion). 
It is now well accepted by the stroke research community that NXY-059 being a hydrophilic compound that does not readily cross the blood brain barrier (BBB) was an inferior compound to develop to treat stroke and that much of the preclinical and translational data overestimated the efficacy of the drug [52-54]. Moreover, the time to treatment used in the SAINT clinical trial may have exceeded a realistic therapeutic window to achieve efficacy $[52,53]$.

Can a monotherapy be developed which has multiple targets? Yes, but this challenge will require a dramatic change in methodologies to develop drugs. The ischemic cascade, which has been elucidated over has been extensively reviewed in the literature $[41,42,55]$. There is a distinct temporal profile of cascade activation following an ischemic stroke that results in a central ischemic core and a penumbral area, which is one of the targets for neuroprotective agents are being developed [47, 48, 56]. Since there are parallel and simultaneous activation of pathways deleterious to tissues at risk, neuronal, glial, and vascular in nature, it has been hypothesized that no single compound will have maximal efficacy and that a multi-target compound or a drug cocktail approach may be needed to promote neuroprotection and recovery of function [57]. In addition, there is a need to counteract the vascular damage that occurs in stroke [57-61]. Thus, success may only come with the application of innovative drug development and screening methods.

"People are different. And it is best that way."

Mark Twain (1835-1910)

\section{Modeling the Heterogeneity of Stroke}

There are two levels of stroke modeling for drug discovery: (1) in vitro screens used to justify further study of a drug and (2) in vivo models used to justify the initiation of a clinical trial. Historically, the in vitro screen has been directed against a single-target enzyme, receptor, protein, or substance, and very often, the goal was to produce a highaffinity ligand toward that "specific target." This approach is relatively effective to treat a condition if a single target is the sole cause of damage or dysfunction, but this is not the case with AIS and this must now be recognized and dealt with.

In this issue of TSR, Lapchak and colleagues report on a unique series of in vitro assays to develop and de-risk drug candidates [62]. The drug of focus in the article is Stilbazulenyl nitrone (STAZN) previously identified and studied in some detail by Ginsberg, Becker, Belayev, and colleagues [63-67]. STAZN, unlike NXY-059, has a low oxidation potential and is 300 times more potent than NXY059 at inhibiting free radical induced peroxidation [65]. In the Lapchak report, STAZN was shown to be a multi-target compound, rather than just act as a free radical scavenger as originally proposed [65]. In two separate in vitro HT-22 hippocampal cell assays, STAZN promoted survival. The first assay used iodoacetic acid (IAA), an irreversible inhibitor of glyceraldehyde 3-phosphate dehydrogenase, which is an enzyme in the glycolytic pathway involved in the synthesis of ATP [68]. The second assay, an oxytosis assay, treated cells with the excitotoxic amino acid glutamate, which in this cell line causes cell death by the depletion of intracellular glutathione (GSH) via inhibition of the cystine/glutamate antiporter $[69,70]$. The article, in addition to a few others published by the same team, illustrates the utility of multiple cell assay screening, including the use of immortalized murine hippocampal HT-22 cells, to discover, characterize, and de-risk multitarget compounds [68, 70-73].

A survey of the scientific literature reveals that there are a few animal models currently being used that can model the heterogeneity of stroke with respect to the diverse population of patients that can present following a stroke. Based upon the original NINDS tPA clinical trial report now published over 15 years ago, the patient population included in the placebo control group had National Institutes of Health Stroke Scale (NIHSS) scores of 1-32 and the active drug group ranged from 1-37 [1]. In essence, both groups had patients that encompassed almost the complete range of the NIHSS scores, which is a 1-to-42-point scale [1,74]. The report details that the victims also had various types of stroke and that IPA was effective in cardioembolic stroke (absolute improvement, 9\%), large vessel stroke (absolute improvement, 15\%), and small vessel stroke (absolute improvement, 14\%) [1]. The recent TOAST analysis demonstrated that tPA efficacy in cardioembolic, thromboembolic, and small vessel lacunar strokes was comparable [75].

There are a few research groups using heterogeneous models of stroke for translational purposes, to assess neuroprotection and/or behavioral improvement [53, 76, 77]. The current gold standard rabbit embolic stroke model [53] is discussed in detail by the Sharp group [78] in this issue of TSR. The authors emphasize the importance of using a heterogeneous animal model of stroke for further stroke drug development using clinically relevant endpoints. Of importance are the following suggestions from the group: (1) Death should be included as an endpoint; (2) if possible, studies should be done in the absence of anesthetics, since commonly used anesthetics have significant neuroprotective properties that may confound data [79-82], and (3) tPA should be used as the gold standard in translational development studies. These three salient points were echoed from a previous perspective article in TSR [53]. 
There are two rabbit model studies in this issue of TSR, one of which studied the effects of dipyridamole on circulation and behavior in rabbits [83] and the second which is a technical study measuring nitrite as a biomarker of AIS [84]. The first study used standard clot placement while under $5 \%$ isoflurane to study the pretreatment effects of dipyridamole. The second study by Silver and Lapchak [84] used a variation of a model described by Lapchak [85]. One point of interest in the study [84] is the absence of anesthetic during embolization and the heterogeneity of infarct distribution (and hemorrhage) in brain following large clot embolization. The distribution is reminiscent of that described in numerous previous publications $[53,86]$. There may be a benefit of such a heterogeneous distribution of infarcts in brain following a stroke and a diverse extent of ischemia in brain. As documented in the NINDS tPA study [1], there is patient population heterogeneity. This type of heterogeneity should be reproduced as much as possible in an animal model to encompass all patients presenting for a clinical trial.

\section{Pleiotropic Drug Discoveries}

This section will focus on three additional examples of new drug strategies to treat stroke. STAZN was previously discussed in a section pertaining to useful in vitro screens to uncover pleiotropic activities. While not approved by the FDA, edaravone is approved by the JMHW and is slated for development in North America [87]. Based upon years of preclinical research, data have accumulated which indicate that edaravone is a multi-target drug that may be useful to treat stroke. Edaravone has recently been reviewed in detail [21]. The benefit of edaravone may be due to its antioxidant activity as well as the regulation of signaling pathways. Edaravone has been shown to suppress apoptosis, counteract microglia-induced neurotoxicity, and reduce the long-term inflammation. As an antioxidant, edaravone inhibits lipid oxidation and suppresses the oxidation of low-density lipoprotein. In animals, edaravone reduces edema, possibly by reducing aquaporin-4 levels. Lastly, edaravone reduces the activity of matrix metalloproteinase-9 (MMP-9), and protect against vascular damage and intracerebral hemorrhage (ICH). Thus, these mechanisms may allow edaravone to prevent neuronal degeneration, vascular compartment damage, and behavioral deficits following a stroke [88].

There is a great deal of literature regarding the beneficial of curcuminoids [89, 90]. Please see the reviews for detailed references [89, 90]. Briefly, like edaravone, curcuminoids have diverse mechanisms of action. Curcumin is an antioxidant, can prevent BBB damage, is also antiapoptotic, and can both block capsase-3 activation and increase $\mathrm{Bcl}-2$. Like edaravone, curcumin reduces edema and is anti-inflammatory. Lastly, it is postulated that curcumin may repair damaged brain pathways by enhancing the levels of endogenous brain-derived neurotrophic factor (BDNF) and activating TrkB-mediated signaling pathway [91, 92]. In a recent study, Lapchak et al. [68] showed that a novel designer curcuminoid CNB-001 with enhanced BBB penetration could attenuate cell death mediated by a variety of insults and maintain mitochondrial function. The drug also attenuated behavioral function deficits following embolic strokes, which were correlated with activation of BDNFrelated signaling mechanisms [68].

The last drug is minocycline, which is reviewed in some detail in this issue of TSR [93]. Minocycline has antiinflammatory properties, anti-apoptotic activity, and is a neuroprotective agent. As described by Fagan et al. [93], the beneficial effects of minocycline are produced via inhibition of inducible form of nitric oxide synthase (iNOS) and mitogen-activated protein (MAP) kinase, inhibition of glutamate toxicity, and inhibition of microglial activation. The anti-apoptotic effects of minocycline are produced through via attenuation of caspase-1 activation. Importantly, minocycline also decreases MMP-9 activity.

Taken together, these are five excellent examples of pleiotropic drugs that can intervene at multiple steps in the ischemic cascade to confer neuroprotection and behavioral improvement. Since it is still early in the development of this class of drug, it is difficult to conclusively list the properties of the best drug that should be designed to treat stroke. The curcuminoids, both curcumin and CNB-001, may have the advantage of promoting neuronal repair by regulating endogenous trophic factors. All of these pleiotropic drugs require additional translational development and de-risking studies $[62,73,94]$ to determine how they can best be used in a clinical situation to provide benefit to stroke victims.

\section{Conclusion}

When one considers the urgency of the situation to develop effective stroke treatment, the quote at the beginning of this editorial, which is attributed to John D. Rockefeller, is more than apropos. As a research community dedicated to providing stroke victims with a choice of effective medical care, we must have the opportunity and funding necessary to explore new treatment strategies that are not on the beaten path. The beaten path approach has not been proven to be successful and has thus failed many stroke victims that enrolled in randomized clinical trials.

As highlighted in this editorial, there may be significant advantages to the use of heterogeneous embolic stroke models for drug evaluation of pleiotropic multi-target compounds because of the complexity of the disease [41, 
42] that we are attempting to treat. A reasonable alternative to the use of pleiotropic multi-target compounds would be combination therapy, a strategy that may be useful clinically [57, 95-97] to provide synergy or increase the therapeutic window or safety profile for tPA. In the foreseeable future, it is even likely that multiple pleiotropic drugs will be combined to treat stroke. We should remain optimistic about the future of therapy development for AIS and continue to explore new scientific strategies to provide optimal care to stroke victims.

Acknowledgments The author was supported by the National Institutes of Neurological Disorders and Stroke Translational Stroke grant 1U01 NS60685-02 (PAL).

\section{References}

1. NINDS. Tissue plasminogen activator for acute ischemic stroke. The National Institute of Neurological Disorders and Stroke rt-PA Stroke Study Group. N Engl J Med. 1995;333(24):1581-7.

2. Petty GW, Brown Jr RD, Whisnant JP, Sicks JD, O'Fallon WM, Wiebers DO. Ischemic stroke subtypes: a population-based study of functional outcome, survival, and recurrence. Stroke. 2000;31 (5):1062-8.

3. Petty GW, Brown Jr RD, Whisnant JP, Sicks JD, O'Fallon WM, Wiebers DO. Ischemic stroke subtypes: a population-based study of incidence and risk factors. Stroke. 1999;30(12):2513-6.

4. Ehrenreich H, Weissenborn K, Prange H, Schneider D, Weimar C, Wartenberg K, et al. Recombinant human erythropoietin in the treatment of acute ischemic stroke. Stroke. 2009;40(12):e647-56.

5. Hacke W, Kaste M, Bluhmki E, Brozman M, Davalos A, Guidetti $\mathrm{D}$, et al. Thrombolysis with alteplase 3 to 4.5 hours after acute ischemic stroke. N Engl J Med. 2008;359(13):1317-29.

6. Hacke W, Kaste M, Fieschi C, Toni D, Lesaffre E, von Kummer R, et al. Intravenous thrombolysis with recombinant tissue plasminogen activator for acute hemispheric stroke. The European Cooperative Acute Stroke Study (ECASS). Jama. 1995;274(13):1017-25.

7. Steiner T, Bluhmki E, Kaste M, Toni D, Trouillas P, von Kummer $\mathrm{R}$, et al. The ECASS 3-hour cohort. Secondary analysis of ECASS data by time stratification. ECASS Study Group. European Cooperative Acute Stroke Study. Cerebrovasc Dis. 1998;8 (4):198-203.

8. Shuaib A, Lees KR, Lyden P, Grotta J, Davalos A, Davis SM, et al. NXY-059 for the treatment of acute ischemic stroke. N Engl J Med. 2007;357(6):562-71.

9. Ingall T. Stroke - incidence, mortality, morbidity and risk. J Insur Med. 2004;36(2):143-52.

10. Lloyd-Jones D, Adams R, Carnethon M, De Simone G, Ferguson TB, Flegal K, et al. Heart disease and stroke statistics-2009 update: a report from the American Heart Association Statistics Committee and Stroke Statistics Subcommittee. Circulation. 2009;119(3):480-6.

11. Lloyd-Jones D, Adams RJ, Brown TM, Carnethon M, Dai S, De Simone G, et al. Executive summary: heart disease and stroke statistics-2010 update: a report from the American Heart Association. Circulation. 2010;121(7):948-54.

12. Lloyd-Jones D, Adams RJ, Brown TM, Carnethon M, Dai S, De Simone G, et al. Heart disease and stroke statistics - 2010 update: a report from the American Heart Association. Circulation. 2010;121(7):e46-e215.
13. AHA. International Cardiovascular Disease Statistics http://www. americanheart.org/downloadable/heart/1177593979236FS06INTL07. pdf. Accessed March 20, 2011.

14. Caro JJ, Huybrechts KF. Stroke Treatment Economic Model (STEM): predicting long-term costs from functional status. Stroke. 1999;30:2574-9.

15. Laffel GL, Braunwald E. Thrombolytic therapy. A new strategy for the treatment of acute myocardial infarction (2). N Engl J Med. 1984;311(12):770-6.

16. Laffel GL, Braunwald E. Thrombolytic therapy. A new strategy for the treatment of acute myocardial infarction (1). N Engl J Med. 1984;311(11):710-7.

17. Schmutzler R, Heckner F, Kortge P, van der Loo J, Pezold A, Poliwoda H, et al. Thrombolytic therapy of recent myocardial infarction. I. Introduction, plan of trial, general clinical results. Ger Med Mon. 1966;11(8):308-14.

18. Poliwoda H. The thrombolytic therapy of acute myocardial infarction. Angiology. 1966;17(8):528-40.

19. Poliwoda H, Diederich KW, Schneider B, Rodenburg R, Heckner $\mathrm{F}$, Kortge $\mathrm{P}$, et al. On the thrombolytic therapy of recent myocardial infarction. 2. Results of electrocardiographic studies. Dtsch Med Wochenschr. 1966;91(21):978-84.

20. Schmutzler R, Heckner F, Kortge P, van de Loo J, Poliwoda H, Pezold FA, et al. On thrombolytic therapy of a recent myocardial infarct. I. Introduction, treatment plans, general clinical results. Dtsch Med Wochenschr. 1966;91(13):581-7.

21. Lapchak PA. A critical assessment of edaravone acute ischemic stroke efficacy trials: is edaravone an effective neuroprotective therapy? Expert Opin Pharmacother. 2010;11(10):1753-63.

22. Lapchak PA. Development of thrombolytic therapy for stroke: a perspective. Expert Opin Investig Drugs. 2002;11(11):1623-32.

23. Schellinger PD, Fiebach JB, Mohr A, Ringleb PA, Jansen O, Hacke W. Thrombolytic therapy for ischemic stroke - a review. Part IIIntra-arterial thrombolysis, vertebrobasilar stroke, phase IV trials, and stroke imaging. Crit Care Med. 2001;29(9):1819-25.

24. Schellinger PD, Fiebach JB, Mohr A, Ringleb PA, Jansen O, Hacke W. Thrombolytic therapy for ischemic stroke-a review. Part I-Intravenous thrombolysis. Crit Care Med. 2001;29 (9):1812-8

25. Verstraete M. Newer thrombolytic agents. Ann Acad Med Singapore. 1999;28(3):424-33.

26. Christou I, Alexandrov AV, Burgin WS, Wojner AW, Felberg RA, Malkoff $\mathrm{M}$, et al. Timing of recanalization after tissue plasminogen activator therapy determined by transcranial doppler correlates with clinical recovery from ischemic stroke. Stroke. 2000;31 (8):1812-6.

27. Mishra NK, Albers GW, Davis SM, Donnan GA, Furlan AJ, Hacke W, et al. Mismatch-based delayed thrombolysis: a metaanalysis. Stroke. 2010;41(1):e25-33.

28. Alexandrov AV, Schellinger PD, Saqqur M, Barreto A, Demchuk AM, Ribo M. Reperfusion and outcomes in Penumbra vs. systemic tissue plasminogen activator clinical trials. Int J Stroke. 2011;6(2):118-22.

29. Molina CA. Reperfusion therapies for acute ischemic stroke: current pharmacological and mechanical approaches. Stroke. 2011;42(1 Suppl):S16-9.

30. Bhatia R, Hill MD, Shobha N, Menon B, Bal S, Kochar P, et al. Low rates of acute recanalization with intravenous recombinant tissue plasminogen activator in ischemic stroke: real-world experience and a call for action. Stroke. 2010;41(10):2254-8.

31. Pandian JD. Re-canalization in acute ischemic stroke: the strategies. Neurol India. 2009;57(1):20-7.

32. Soltani A, Clark WM, Hansmann DR. Sonothrombolysis: an emerging modality for the treatment of acute ischemic and hemorrhagic stroke. Transl Stroke Res. 2011;2(2). doi:10.1007/ s12975-011-0077-1. 
33. Fang MC, Cutler DM, Rosen AB. Trends in thrombolytic use for ischemic stroke in the United States. J Hosp Med. 2010;5(7):4069.

34. Reeves MJ, Arora S, Broderick JP, Frankel M, Heinrich JP, Hickenbottom S, et al. Acute stroke care in the US: results from 4 pilot prototypes of the Paul Coverdell National Acute Stroke Registry. Stroke. 2005;36(6):1232-40.

35. Lansberg MG, Bluhmki E, Thijs VN. Efficacy and safety of tissue plasminogen activator 3 to 4.5 hours after acute ischemic stroke: a metaanalysis. Stroke. 2009;40(7):2438-41.

36. Lees KR, Bluhmki E, von Kummer R, Brott TG, Toni D, Grotta $\mathrm{JC}$, et al. Time to treatment with intravenous alteplase and outcome in stroke: an updated pooled analysis of ECASS, ATLANTIS, NINDS, and EPITHET trials. Lancet. 2010;375 (9727):1695-703.

37. Toyoda K, Koga M, Naganuma M, Shiokawa Y, Nakagawara J, Furui E, et al. Routine use of intravenous low-dose recombinant tissue plasminogen activator in Japanese patients: general outcomes and prognostic factors from the SAMURAI register. Stroke. 2009;40(11):3591-5.

38. Yamaguchi T, Mori E, Minematsu K, Nakagawara J, Hashi K, Saito I, et al. Alteplase at $0.6 \mathrm{mg} / \mathrm{kg}$ for acute ischemic stroke within 3 hours of onset: Japan Alteplase Clinical Trial (J-ACT). Stroke. 2006;37(7):1810-5.

39. Otomo E. Effect of a novel free radical scavenger, edaravone (MCI-186), on acute brain infarction. Randomized, placebocontrolled, double-blind study at multicenters. Cerebrovasc Dis. 2003;15(3):222-9.

40. Sinha M, Anuradha H, Juyal R, Shukla R, Garg R, Kar A. Edaravone in acute ischemic stroke, an Indian experience. Neurol Asia. 2009; 14:7-10.

41. Dirnagl U, Iadecola C, Moskowitz MA. Pathobiology of ischaemic stroke: an integrated view. Trends Neurosci. 1999;22 (9):391-7.

42. Moskowitz MA, Lo EH, Iadecola C. The science of stroke: mechanisms in search of treatments. Neuron. 2010;67(2):181-98.

43. Lipton P. Ischemic cell death in brain neurons. Physiol Rev. 1999;79(4):1431-568.

44. Lapchak PA, De Taboada L. Transcranial near infrared laser treatment (NILT) increases cortical adenosine-5'-triphosphate (ATP) content following embolic strokes in rabbits. Brain Res. 2010;1306:100-5.

45. Floyd RA. Antioxidants, oxidative stress, and degenerative neurological disorders. Proc Soc Exp Biol Med. 1999;222 (3):236-45

46. Back T. Pathophysiology of the ischemic penumbra-revision of a concept. Cell Mol Neurobiol. 1998;18(6):621-38.

47. Fisher M. The ischemic penumbra: identification, evolution and treatment concepts. Cerebrovasc Dis. 2004;17:1-6.

48. Michel P, Bogousslavsky J. Penumbra is brain: no excuse not to perfuse. Ann Neurol. 2005;58(5):661-3.

49. Ferguson KN, Kidwell CS, Starkman S, Saver JL. Hyperacute treatment initiation in neuroprotective agent stroke trials. J Stroke Cerebrovasc Dis. 2004;13(3):109-12.

50. Lees KR, Zivin JA, Ashwood T, Davalos A, Davis SM, Diener $\mathrm{HC}$, et al. NXY-059 for acute ischemic stroke. N Engl J Med. 2006;354(6):588-600.

51. Watanabe T, Tahara M, Todo S. The novel antioxidant edaravone: from bench to bedside. Cardiovasc Ther. 2008;26(2):101-14.

52. Bath PM, Gray LJ, Bath AJ, Buchan A, Miyata T, Green AR. Effects of NXY-059 in experimental stroke: an individual animal meta-analysis. Br J Pharmacol. 2009;157(7):1157-71.

53. Lapchak PA. Translational stroke research using a rabbit embolic stroke model: a correlative analysis hypothesis for novel therapy development. Transl Stroke Res. 2010;1(2):96-107. Perspective Review.
54. Savitz SI. A critical appraisal of the NXY-059 neuroprotection studies for acute stroke: a need for more rigorous testing of neuroprotective agents in animal models of stroke. Exp Neurol. 2007;205(1):20-5.

55. Shaller CA, Jacques S, Shelden $\mathrm{CH}$. The pathophysiology of stroke: a review with molecular considerations. Surg Neurol. 1980;14(6):433-43.

56. Muir KW. Heterogeneity of stroke pathophysiology and neuroprotective clinical trial design. Stroke. 2002;33(6):1545-50.

57. Lapchak PA, Araujo DM. Advances in ischemic stroke treatment: neuroprotective and combination therapies. Expert Opin Emerg Drugs. 2007;12(1):97-112.

58. Lo EH, Rosenberg GA. The neurovascular unit in health and disease: introduction. Stroke. 2009;40(3 Suppl):S2-3.

59. Zhao BQ, Tejima E, Lo EH. Neurovascular proteases in brain injury, hemorrhage and remodeling after stroke. Stroke. 2007;38(2 Suppl):748-52.

60. Chen B, Friedman B, Cheng Q, Tsai P, Schim E, Kleinfeld D, et al. Severe blood-brain barrier disruption and surrounding tissue injury. Stroke. 2009;40(12):e666-74.

61. Sierra C, Coca A, Schiffrin EL. Vascular mechanisms in the pathogenesis of stroke. Curr Hypertens Rep. 2011. doi:10.1007/ s11906-011-0195-x

62. Lapchak PA, Schubert D, Maher P. De-risking of Stilbazulenyl nitrone (STAZN), a lipophilic nitrone to treat stroke using a unique panel of in vitro assays. Transl Stroke Res. 2011;2(2). doi:10.1007/s12975-011-0071-7.

63. Becker DA. Diagnostic and therapeutic applications of azulenyl nitrone spin traps. Cell Mol Life Sci. 1999;56(7-8):626-33.

64. Becker DA. Azulenyl nitrone spin trapping agents, methods of making and using same. U.S. Patent 6,291,702

65. Becker DA, Ley JJ, Echegoyen L, Alvarado R. Stilbazulenyl nitrone (STAZN): a nitronyl-substituted hydrocarbon with the potency of classical phenolic chain-breaking antioxidants. J Am Chem Soc. 2002;124(17):4678-84.

66. Belayev L, Becker DA, Alonso OF, Liu Y, Busto R, Ley JJ, et al. Stilbazulenyl nitrone, a novel azulenyl nitrone antioxidant: improved neurological deficit and reduced contusion size after traumatic brain injury in rats. J Neurosurg. 2002;96(6):1077-83.

67. Ginsberg MD, Becker DA, Busto R, Belayev A, Zhang Y, Khoutorova $\mathrm{L}$, et al. Stilbazulenyl nitrone, a novel antioxidant, is highly neuroprotective in focal ischemia. Ann Neurol. 2003;54(3):330-42.

68. Lapchak PA, Schubert DR, Maher PA. Delayed treatment with a novel neurotrophic compound reduces behavioral deficits in rabbit ischemic stroke. J Neurochem. 2011;116(1):122-31.

69. Tan S, Schubert D, Maher P. Oxytosis: A novel form of programmed cell death. Curr Top Med Chem. 2001;1(6):497-506.

70. Liu Y, Dargusch R, Maher P, Schubert D. A broadly neuroprotective derivative of curcumin. J Neurochem. 2008;105(4):1336-45.

71. Lapchak PA, Maher P, Schubert D, Zivin JA. Baicalein, an antioxidant 12/15 lipoxygenase inhibitor improves clinical rating scores following multiple infarct embolic strokes. Neuroscience. 2007;150(3):585-91.

72. Maher P, Salgado KF, Zivin JA, Lapchak PA. A novel approach to screening for new neuroprotective compounds for the treatment of stroke. Brain Res. 2007;1173:117-25.

73. Lapchak PA. KcKim, J.M. CeeTox ${ }^{\mathrm{TM}}$ analysis of CNB-001 a novel curcumin-based neurotrophic/neuroprotective lead compound to treat stroke: comparison with NXY-059 and Radicut. Transl Stroke Research. 2011;2(1):51-9.

74. Lyden P, Lu M, Jackson C, Marler J, Kothari R, Brott T, et al. Underlying structure of the National Institutes of Health Stroke Scale: results of a factor analysis. Stroke. 1999;30:2347.

75. Hsia AW, Sachdev HS, Tomlinson J, Hamilton SA, Tong DC. Efficacy of IV tissue plasmingogen activator in acute stroke: does stroke subtype really matter? Neurology. 2002;61(1):71-5. 
76. Brown AT, Skinner RD, Flores R, Hennings L, Borrelli MJ, Lowery J, et al. Stroke location and brain function in an embolic rabbit stroke model. J Vasc Interv Radiol. 2010;21:903-9.

77. Guluma KZ, Lapchak PA. Comparison of the post-embolization effects of tissue-plasminogen activator and simvastatin on neurological outcome in a clinically relevant rat model of acute ischemic stroke. Brain Res. 2010;1354:206-16.

78. Turner R, Jickling, G, Sharp, F Are underlying assumptions of current animal models of human stroke correct: from STAIRS to high hurdles? Transl Stroke Res. 2011;2(2). doi:10.1007/s12975011-0067-3.

79. Kawaguchi M, Furuya H, Patel PM. Neuroprotective effects of anesthetic agents. J Anesth. 2005;19(2):150-6.

80. Koerner IP, Brambrink AM. Brain protection by anesthetic agents. Curr Opin Anaesthesiol. 2006;19(5):481-6.

81. Matchett GA, Allard MW, Martin RD, Zhang JH. Neuroprotective effect of volatile anesthetic agents: molecular mechanisms. Neurol Res. 2009;31(2):128-34.

82. Nishikawa K, MacIver MB. Excitatory synaptic transmission mediated by NMDA receptors is more sensitive to isoflurane than are non-NMDA receptor-mediated responses. Anesthesiology. 2000;92(1):228-36.

83. d'Esterre C, Tichauer K, Aviv R, Eisert W, Lee T-Y. Dipyridamole treatment prior to stroke onset: examining post-stroke cerebral circulation and outcome in rabbits Transl Stroke Res. 2011;2(2). doi:10.1007/s12975-010-0062-0.

84. Silver JH, Lapchak PA. Continuous Monitoring of Changes in Plasma Nitrite following Cerebral Ischemia in a Rabbit Embolic Stroke Model. Transl Stroke Res. 2011;2(2). doi:10.1007/s12975-011-0073-5.

85. Lapchak PA. A new embolus injection method to evaluate intracerebral hemorrhage in New Zealand white rabbits. Brain Res. 2010;1349C:129-36.

86. Brown AT, Skinner RD, Flores R, Hennings L, Borrelli MJ, Lowery J, et al. Stroke location and brain function in an embolic rabbit stroke model. J Vasc Interv Radiol. 2010;21(6):903-9.
87. Clinicaltrials.gov: MCI-186. http://clinicaltrials.gov/ct2/show/ NCT00821821. Accessed March 19, 2011

88. Lapchak PA, Zivin JA. The lipophilic multifunctional antioxidant edaravone (radicut) improves behavior following embolic strokes in rabbits: a combination therapy study with tissue plasminogen activator. Exp Neurol. 2009;215(1):95-100.

89. Cole GM, Teter B, Frautschy SA. Neuroprotective effects of curcumin. Adv Exp Med Biol. 2007;595:197-212.

90. Lapchak PA. Neuroprotective and neurotrophic curcuminoids to treat stroke: a translational perspective. Expert Opin Investig Drugs. 2011;20(1):13-22.

91. Wang R, Li YB, Li YH, Xu Y, Wu HL, Li XJ. Curcumin protects against glutamate excitotoxicity in rat cerebral cortical neurons by increasing brain-derived neurotrophic factor level and activating TrkB. Brain Res. 2008;1210:84-91.

92. Wang R, Li YH, Xu Y, Li YB, Wu HL, Guo H, et al. Curcumin produces neuroprotective effects via activating brain-derived neurotrophic factor/TrkB-dependent MAPK and PI-3K cascades in rodent cortical neurons. Prog Neuropsychopharmacol Biol Psychiatry. 2010;34(1):147-53.

93. Fagan SC, Cronic LE, Hess DC. Minocycline Development for Acute Ischemic Stroke. Transl Stroke Res. 2011;2(2). doi:10.1007/ s12975-011-0072-6.

94. McKim Jr JM. Building a tiered approach to in vitro predictive toxicity screening: a focus on assays with in vivo relevance. Comb Chem High Throughput Screen. 2010;13(2):188-206.

95. Recommendations for clinical trial evaluation of acute stroke therapies. Stroke. 2001;32(7):1598-606.

96. O'Collins VE, Macleod MR, Cox SF, Van Raay L, Aleksoska E, Donnan GA, et al. Preclinical drug evaluation for combination therapy in acute stroke using systematic review, meta-analysis, and subsequent experimental testing. J Cereb Blood Flow Metab. 2011;31:962-975.

97. Fisher M. New approaches to neuroprotective drug development. Stroke. 2011;42(1 Suppl):S24-7. 